\title{
MAIN PRINCIPLES OF THE NPEMFE METHOD EMPLOYMENT FOR DECISION OF DIFFERENT PROBLEMS OF MINING GEOMECHANICS AT MINES OF DONBASS.
}

\author{
Kuznetsov I.V., Osykin M.K. \\ Ukraine, Institute of mineral resourses, Simferopol
}

\section{GENERAL INFORMATION ON PROBLEMS OF DONBASS COAL MINING}

The Donbass region is characterized by enough complex mining-geomechanic conditions of an underground coal mining, beds of which are subjected to tectonical, plicative dislocations with a break in continuity, complicating a picture of stresses distribution around working. Besides, the long coal mining during many decades on horizons from $300-400 \mathrm{~m}$ to $1 \mathrm{~km}$ and more causes the problem of old abandoned underground working revealing, under which cauldrons dangerous for engineering constructions, are formed.

The task of revealing of subsidence-dangerous sections of rock masses above modern horizons, being developed, that cause destabilization of the earth surface,especially in zones of local microamplitude dislocations with a break in continuity is also a matter of current interest.

The problem of a stressed state evaluation of rock pillars, left in mines, that are assigned to preservation of a rock mass stability above important national economic projects, is also of a great practical interest.

Original results of geophysical express investigations, stated below, are dedicated to decision of various aspects of above-mentioned problems on the basis of the study, from the earth surface and under underground conditions, of objective regularities of rocks pulse electromagnetic emission manifestation, arising in them under the action of stress fields, formed in workings and above them.

\section{Results of variations measurements of the natural pulse electromagnetic field of the Earth (NPEMFE) with the purpose of revealing and evaluation of tectonic dislocation zones on developing territories}

Measurements of NPEMFE under underground conditions were carried out at one of the Donbass mines on the district of crosscut (horizon 930), confined (in space) to a tectonically active zone, within the limits of which during the process of a driving high-amplitude dislocations of a fault type, complicated by a system of younger microamplitude faults have been revealed.

As a plot of NPEMFE changings along the investigated district crosscut, dislocations crossed by it, have an obvious connection with anomalous manifestations of NPEMFE (Fig.1). Besides, as a rule, microamplitude dislocations (faults of the 2nd and more high orders), forming in hanging stressed limbs of primary regional faults, are displayed by high of NPEMFE (with an amplitude of anomaly $\mathrm{A}>=5$ ). Blocks of rocks, disposed in the zone of the regional fault, are less stressed or are in almost relaxed state.(Fig.1)

Hence, it is possible to evaluate the degree of activity of dislocations and, thereby, to determine the least stable section of the working roof in zones of dislocations by character of intensity differentiation of the pulse electromagnetic emission of rocks, fixed in underground workings.

In this mine underground measurements of NPEMFE were carried out also with the purpose to evaluate the stressed state of a coal-bearing bed at the section of tectonic flexure dislocation (horizon 970).In the process of driving here the flexure of a fault type, having uplifted, common, steeply dipping and dropped sides has been stripped.(Yaroshevski V., 1981).

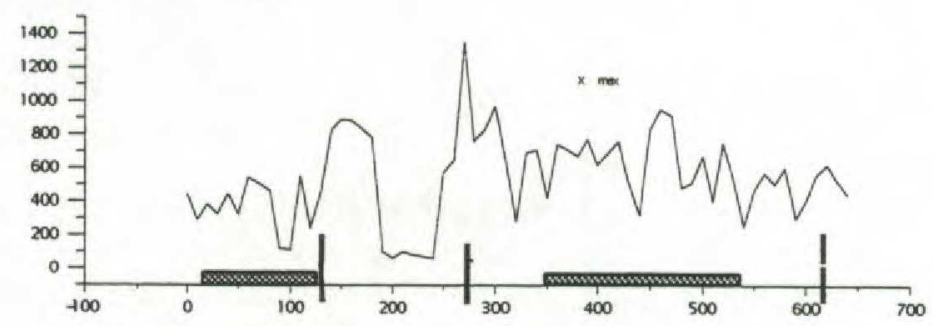

Fig.1 Changing of NPEMFE along the crosscut, traversing zones of tectonic dislocation

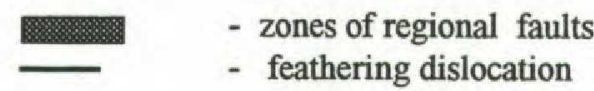


The peculiarities of the working stressed state, revealed by characteristic changing of NPEMFE, have a natural explanation. The increased and high values of the electromagnetic radiation (EMR) at the section of a rise (amplitude of anomaly regarding normal background is $A>3-5$ ).

The common limb is characterized by low values of EMR velocity, and a dropped side had a very low level of electromagnetic activity of rocks. The registered natural changings of NPEMFE in structural elements of a flexure are explained by the geomechanics of a dislocations- an uplifted side,- subjected to influence of uplifting tectonic forces, is in a state of stresses accumulation; in a thrown (dropped) side the stresses were relaxed in the process of the fault. Hence, the sharp change (reduction) of EMR intensity, observed in the working, is a sign of an alternation of geostructural conditions of the coal bed occurrence. Taking into considerations, that this effect of NPEMFE changing was registered $150-200 \mathrm{~m}$ from the flexure- fault dislocation ("diving" of the bed), this sign might be considered as the forecasting, one during the evaluation of possible unfavourable geostructural conditions for the driving.

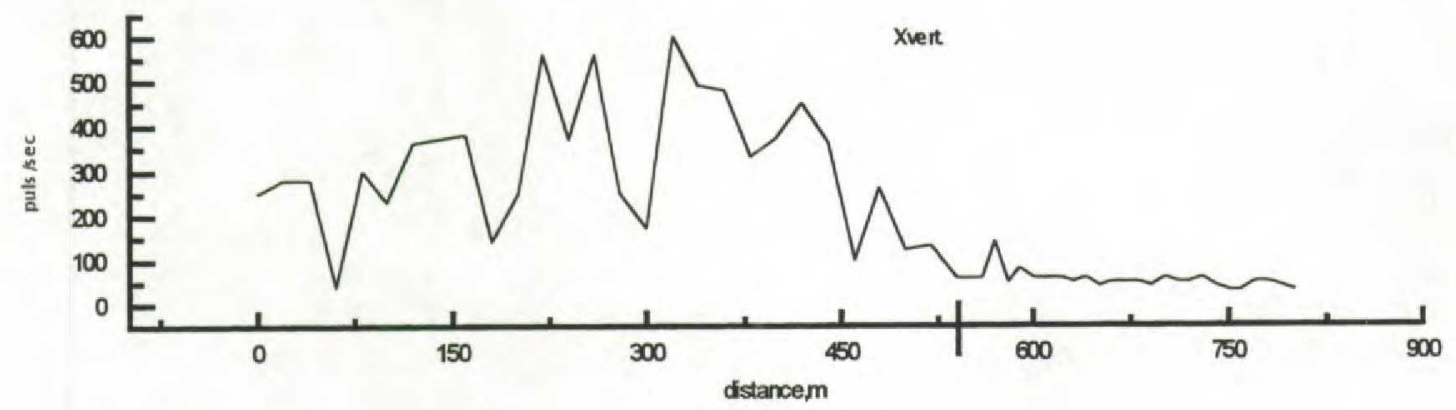

Fig. 2 Changing of NPEMFE along the working, dissecting the flexure dislocation

- a flexure axis

\section{Evaluation of dynamical influence zones of modern and old mining workings with the purpose of determining the spatial borders of subsidence processes development above them}

Investigations of stress fields distributions peculiarities, registered by NPEMFE variations, were carried out above working, worked out in 1995 and 1996 and been in the period of work under different reological condition.

Above the working, worked out in 1995 , a forming cauldron during 1,5 years, reached a certain stage of consolidation, during which in the central part the zone of contraction was formed, and, in peripheral parts the zone of extension was formed.

Such directivity of the special development of surface deformations is reflected in a corresponding, rather contrast, distribution of stresses (Fig. 3 ) registered by NPEMFE intensity, measured at the surface. A level of stress field has the highest values directly above worked out longwall (horison $930 \mathrm{~m}$ ). The width of the dynamical influence zone by spatial variations of different parameters is $250-400 \mathrm{~m}$. Moreover, values of NPEMFE parameters undergo small variations in the zone of the working borders, as of the most unstable rock mass sections, where the origination of deformations seats takes place.

Somewhat another character of NPEMFE parameters changing is observed on a profile, running above the longwall, developed during measurements, when the formation process of the dynamical influence zone was on the initial stage. At this stage, when elastic deformations prevail, the rock mass subsides as a single body, the borders of which are deforming zone of a microjointing above banks of the longwall, being developed. That's why on profils of NPEMFE registration (Fig. 4 ) anomalous manifestations of the pulse, electromagnetic field parameters are directed to borders of the developed space.

Hence, the contrast range of the stress field distribution, registered by NPEMFE above developed underground spaces, expressed as corresponding sizes, shapes and amplitudes of the electromagnetic radiation positive anomalies, depends on the stage of rock mass consolidation above working. Besides, borders of the dynamical influence zones of underground workings are displayed by corresponding anomalous changing of NPEMFE parameters. The example of the successful employment of the NPEMFE registration method for revealing of old mine shafts from the surface that are mapped by an anomalous electromagnetic radiation in the zone of the shaft fall is shown also on Fig.5. 

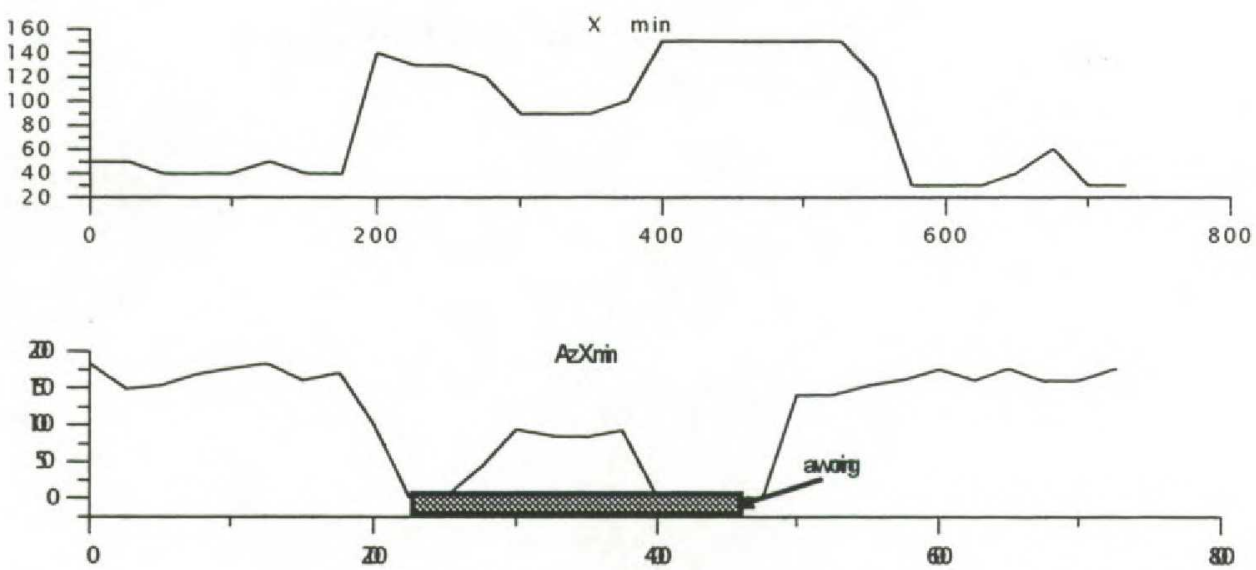

Fig. 3. Changing of NPEMFE along the profile running
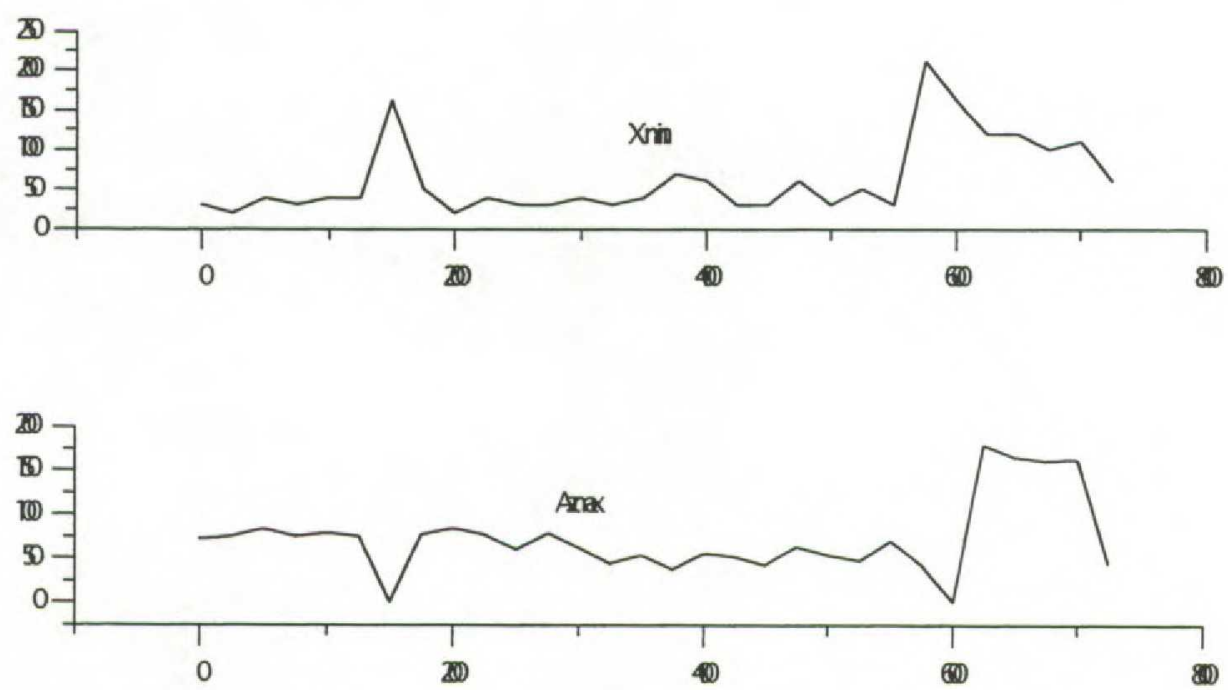

Fig.4 Changing of NPEMFE along the profile,running above the mine, developed to the moment of measurements (1996)

\section{Evaluation of the stressed state of rocks security pillars}

Investigations of NPEMFE variations in zone of security pillars were carried out with the purpose of determination of the degree of their underworking influence on dimensions of strained zones, concentrating in rocks of pillars.

The example of effectual decision of this problem on evaluation of the pillar stressed state level in the underworked longwall is shown on Fig. 6. By an amplitude and dimensions of the NPEMFE it is possible to judge about probability of the rock pillar destruction and about its dimension optimization.

Thus, on the basis of investigations results in Donbass, the possibility of effectual employment of the NPEMFE method for decision of different geomechanics problems in a mining business: evaluating of the stressed state of rock masses above underworked spaces, mapping of subsidence processes above them, revealing of dislocations zones, determination of working and security pillars stressed state has been shown. 

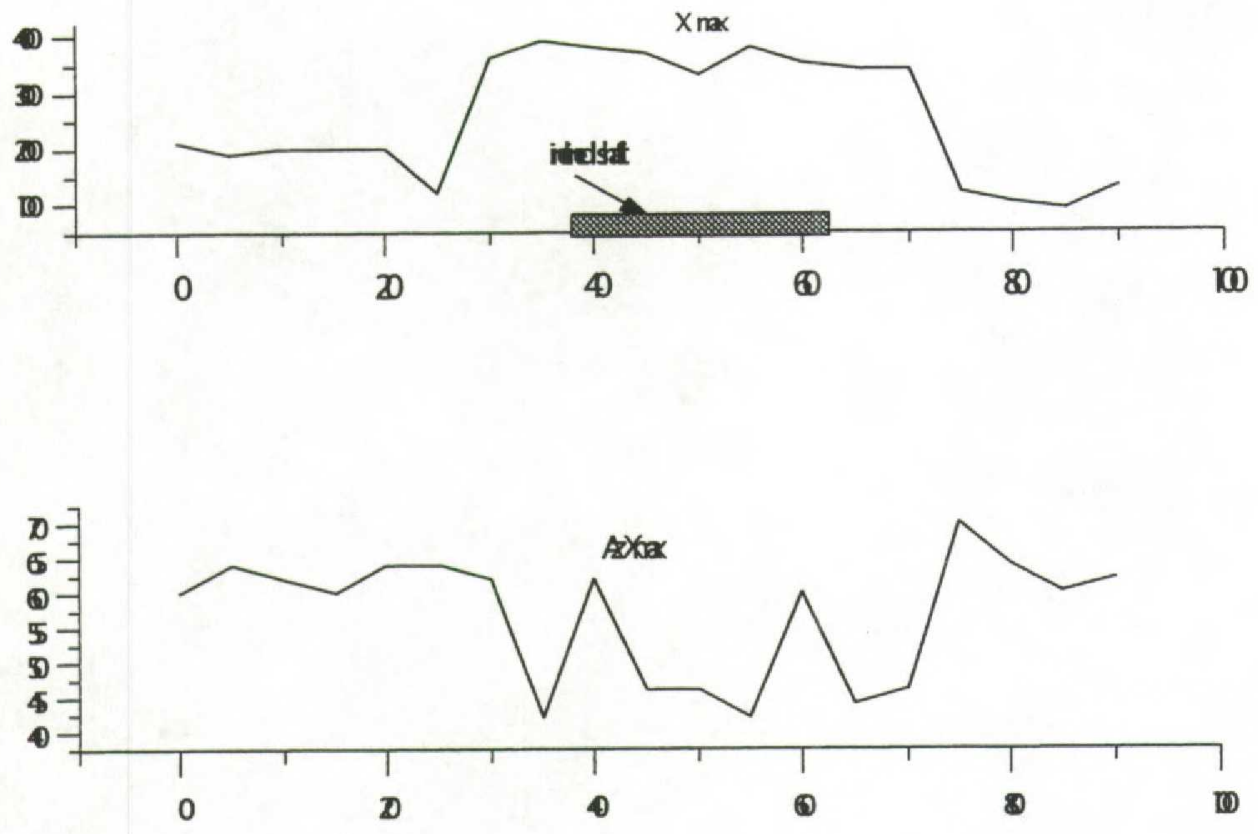

Fig.5. The plot of NPEMFE changing above the inclined shaft.

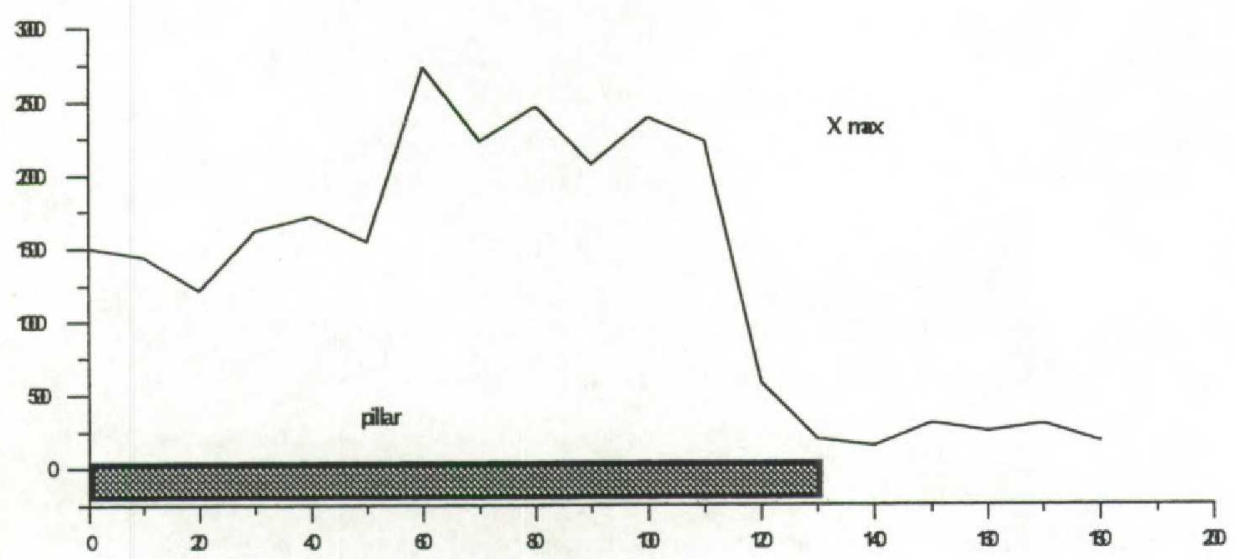

Fig.6. Changing of NPEMFE in the support pillar 